
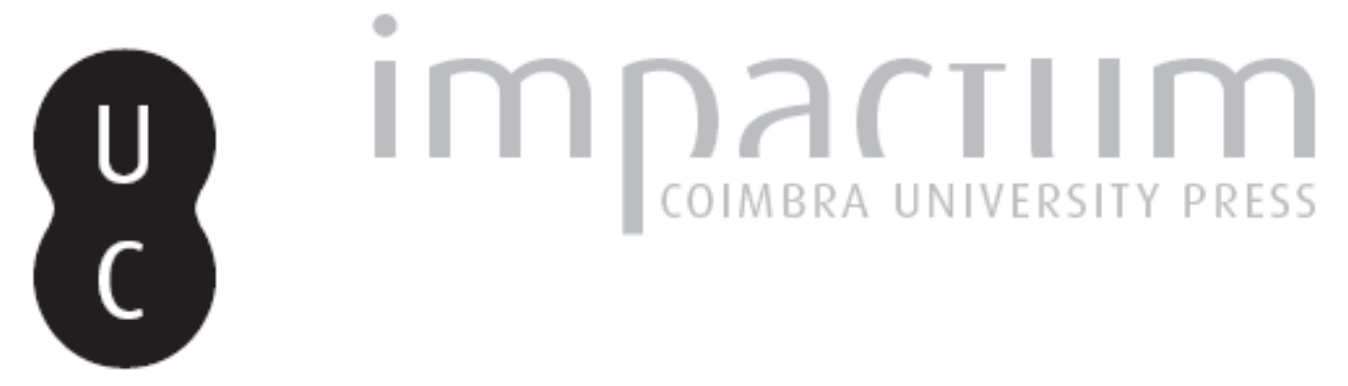

\title{
[Recensão a] Daniele Pasquinucci e Luca Verzichelli, Elezione europee e classe politica sovranazionale 1979-2004
}

Autor(es): $\quad$ Vargues, Isabel Nobre

Publicado por: Imprensa da Universidade de Coimbra

URL persistente:

URI:http://hdl.handle.net/10316.2/43709

DOI:

DOI:https://doi.org/10.14195/2183-8925_25_18

Accessed : $\quad$ 26-Apr-2023 16:23:57

A navegação consulta e descarregamento dos títulos inseridos nas Bibliotecas Digitais UC Digitalis, UC Pombalina e UC Impactum, pressupõem a aceitação plena e sem reservas dos Termos e Condições de Uso destas Bibliotecas Digitais, disponíveis em https://digitalis.uc.pt/pt-pt/termos.

Conforme exposto nos referidos Termos e Condições de Uso, o descarregamento de títulos de acesso restrito requer uma licença válida de autorização devendo o utilizador aceder ao(s) documento(s) a partir de um endereço de IP da instituição detentora da supramencionada licença.

Ao utilizador é apenas permitido o descarregamento para uso pessoal, pelo que o emprego do(s) título(s) descarregado(s) para outro fim, designadamente comercial, carece de autorização do respetivo autor ou editor da obra.

Na medida em que todas as obras da UC Digitalis se encontram protegidas pelo Código do Direito de Autor e Direitos Conexos e demais legislação aplicável, toda a cópia, parcial ou total, deste documento, nos casos em que é legalmente admitida, deverá conter ou fazer-se acompanhar por este aviso.

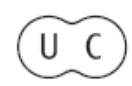



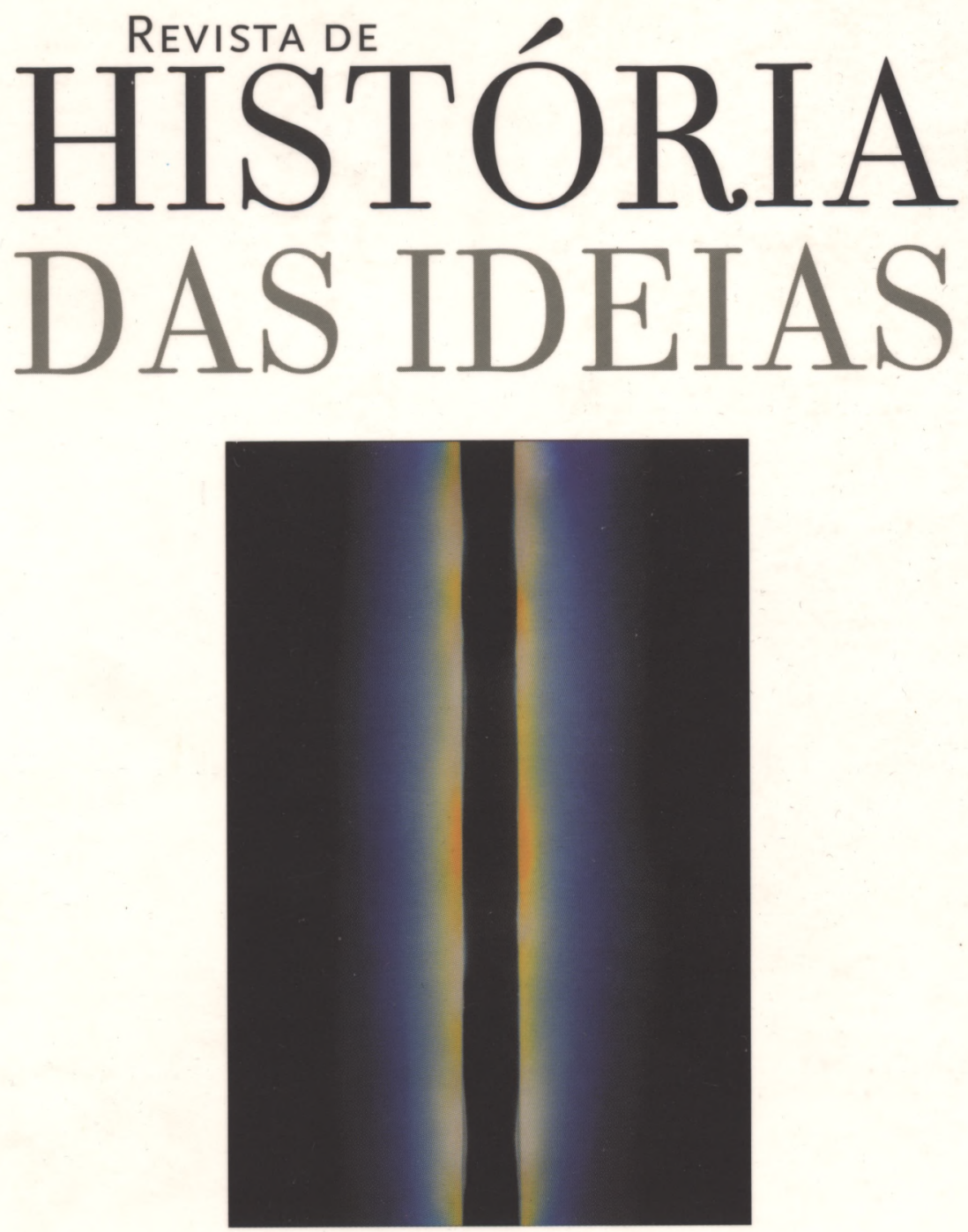

TOLERÂNCIAS, INTOLERÂNCIAS

\author{
Volume 25, 2004
}

INSTITUTO DE HISTÓRIA E TEORIA DAS IDEIAS

Faculdade de Letras da Universidade de CoImbra 
Daniele Pasquinucci e Luca Verzichelli, Elezione europee e classe politica sovranazionale 1979-2004, Bologna, il Mulino, 2004, 294 pp.

A história da construção europeia, em particular no âmbito da história da cidadania, do federalismo e da integração europeias, tem sido, desde finais do século $X X$, um actual objecto de debate e de estudo concretizado em realizações científicas e culturais, de diversa natureza tais como Colóquios, Seminários e Masters, que têm acompanhado e incentivado a investigação em torno de um melhor conhecimento sobre o processo político de construção da Europa. É o caso, por exemplo, do Master in Human Rights, coordenado pela Universidade de Pavia e do Master in European Studies, coordenado pela Universidade de Siena e já em 5 a edição, os quais constituem hoje interessantes laboratórios de investigação sobre as realidades europeias nesses domínios partilhados por diversas Universidades, entre as quais a de Coimbra, graças ao dinamismo dos seus coordenadores. Inúmeras publicações têm sido o resultado dessas reflexões em várias instituições universitárias europeias. Entre elas destaca-se em Itália a colecção " Storia del Federalismo e dell'integrazione europeia" com mais de uma dezena de títulos publicados até hoje.

Um dos mais recentes livros sobre essas temáticas surge justamente como contributo do Departamento de Ciência Histórica, Jurídica, Política e Social do Centro di Ricerca sull'integrazione europea, da Universidade de Siena e é da autoria de dois professores: Daniele Pasquinucci é professor associado de História Contemporânea na Universidade de Siena e dedica-se ao estudo da história da integração europeia; Luca Verzichelli é professor associado de Ciência Política na mesma Universidade e dedica-se ao estudo das instituições e das elites políticas na Europa.

O livro está dividido em duas partes distintas. Daniele Pasquinucci é Autor da primeira parte intitulada "As eleições europeias 1979-1999" tema que desenvolve ao longo dos quatro capítulos iniciais: as eleições europeias entre história e interpretação (cap. I); as regras do jogo. Do procedimento eleitoral uniforme aos "princípios comuns" (cap. II); as campanhas eleitorais (cap. III); os resultados eleitorais (cap. IV).

Luca Verzichelli é Autor da segunda parte intitulada "A classe política no Parlamento Europeu", tema que desenvolve ao longo de mais três capítulos: classe política e Parlamento Europeu. Questões teóricas e objectivos de investigação (cap. V); os parlamentares europeus em 1979 (cap. VI); para uma "classe política supranacional"? Os parlamentares 
europeus, vinte e cinco anos depois da primeira eleição directa (cap. VII). A conclusão deste estudo intitula-se "Perspectivas de investigação depois de 2004". O texto inclui alguns gráficos, quadros e notas de rodapé que muito contribuem para uma melhor compreensão dos temas em estudo bem como um útil índice onomástico. As referências bibliográficas estão inseridas ao longo das notas de rodapé.

Passados vinte e cinco anos da primeira eleição directa do Parlamento Europeu (1979), por sufrágio universal, várias são as questões que podem ser analisadas: por exemplo, haverá já uma identidade "euronacional"? Há uma classe política europeia? Outras não menos importantes questões como a da participação eleitoral dos cidadãos europeus e/ou o impacto das eleições europeias na construção política da União Europeia ganham uma nova dimensão, em Julho de 1979, quando os então novos estados membros elegeram, pela primeira vez na história da Europa os 410 deputados parlamentares por sufrágio universal.

Como sabemos é desde essa data que o Parlamento Europeu, com sede em Estrasburgo, tem sido eleito de cinco em cinco anos $(1979,1984$, 1989, 1994, 1999 e 2004), simultaneamente em todos os países da Europa e desde então o número de deputados, após os vários alargamentos, não deixou de crescer até hoje. As campanhas eleitorais de 1979 a 1999 nos vários estados-membros, as percentagens de votantes, os grupos políticos no Parlamento Europeu foram estudados com grande rigor tendo presente as mudanças na Europa e no Mundo. O Tratado de Amsterdão fixou em 700 o número de deputados, número que, numa perspectiva futura, implicará certamente uma nova reflexão.

O Parlamento, a Comissão e o Conselho Europeus são as forças motrizes na União Europeia e quanto maior for o conhecimento em torno dos seus mecanismos de funcionamento, as eleições e os grupos políticos em particular, mais se incrementarão todos os actos da democracia e se contribuirá para a emergência de uma classe política supranacional.

A actualidade e a seriedade da pesquisa agora publicada facilitará, sem dúvida, a formação política do cidadão europeu. 